\title{
Community College Focus Group: Comments from the 2000 ALA Midwinter Meeting
}

Demonstrating dedication to their profession, 12 members of ACRL's Community and Junior College Libraries Section (CJCLS) agreed to meet very early Saturday, January 15,2000 , (as part of a focus group sponsored by the ACRL Board of Directors) during the ALA Midwinter Meeting to discuss their membership in ACRL and what concerns them most as community college librarians.

Past ACRL President William Miller generously agreed to facilitate the active discussion and the participants eloquently spoke of their concerns. While the discussion began with looking at why community college librarians join ACRL, certain issues and matters were clearly uppermost in the members' minds. Professional development and advocacy within higher education appeared to be strong concerns, as well as collaboration with other community college associations.

Below are a few of the comments made during the discussion.

\section{Membership}

- "I joined ACRL after attending a National Conference. The ACRL National Conference is more focused and relevant to my work."

"Initially, I joined for the journals. I wanted my own copy."

"CJCLS was the only group I could find specifically for community college librarians. It's important for community college librarians to network with each other and to keep in touch with librarians at fouryear schools."

"The Immersion program [ACRL Institute for Information Literacy (IIL) Immersion Programs] attracted me to ACRL."

IU staff will convert 800,000 microfilm page images to text files using optical character recognition software and create a searchable database of the texts. Participating libraries will edit, encode, and proofread the text files.

The nine libraries working on this project are members of the Committee on Institu-
"Many of my colleagues don't belong to ACRL because of limited travel funds within community colleges and a lot of competition with other conferences, such as League of Innovation."

\section{Programs and activities}

"I'd like to see more workshops and not just in conjunction with conferences. Regional conferences would be great, especially on hot topics like accreditation."

"A speakers bureau with preplanned workshops would be helpful."

"The Immersion program is great-run with it!"

"ACRL needs to continue collaborating with other organizations and state associations. These collaborations could develop into joint programs for developing the management and administrative skills of community college librarians, as well as making administrators more aware of libraries and getting librarians on accreditation teams and in administrative positions on campus."

"Community colleges don't have a hierarchy that allows community college librarians to learn administration until they are thrown into it."

"With IPEDS no longer requiring libraries to report their statistics, the ACRL 1998 Academic Library Trends and Statistics is even more important. And I love being able to set up my own peer group with the CD-ROM."

ACRL would like to thank all of the focus group participants and William Miller for their time and ideas. The comments and suggestions are greatly appreciated and will be used to improve ACRL services and activities.-Melissa Cast, ACRL, e-mail: mcast@ala.org

tional Cooperation (CIC), an academic consortium of the Big Ten universities and the University of Chicago. Participating libraries are: Indiana, Michigan State, and Ohio State Universities, and the Universities of Illinois at Chicago, of Illinois at Urbana-Champaign, of Iowa, of Michigan, of Minnesota, and of Wisconsin-Madison. 